\title{
A integração disciplinar na ciência da informação: os não-ditos sobre essa familiar desconhecida
}

Edivanio Duarte de Souza

Doutor em ciência da informação pela Escola de Ciência da Informação da Universidade Federal de Minas Gerais - Belo Horizonte, MG - Brasil. Professor do curso de biblioteconomia do Instituto de Ciências Humanas, Comunicação e Artes da Universidade Federal de Alagoas - Maceió, AL - Brasil

Email:<edivanioduarte@cci.ufal.br>

Eduardo José Wense Dias

Doutor em Information Science pela University of California, Los Angeles, Estados Unidos. Professor da Escola de Ciência da Informação. Universidade Federal de Minas Gerais - Belo Horizonte, MG - Brasil

Email:<dias.wense@gmail.com>

\section{Resumo}

Parte considerável dos estudos epistemológicos no campo da ciência da informação, no Brasil, tem como vetor a interdisciplinaridade. Contudo, alguns denunciam a dificuldade nos processos de integração disciplinar e de consolidação epistemológica. Eles têm por fundamento a construção de indicadores bibliométricos, excluindo o funcionamento discursivo que evidencia os efeitos de sentido dele decorrentes. Este trabalho visa a compreender esses efeitos, a partir dos implícitos e silenciamentos na constituição desse discurso e nos possíveis entraves à consolidação epistemológica da ciência da informação. Para tanto, tem como corpus analítico 12 (doze) artigos selecionados na produção científica brasileira que discutem a integração disciplinar na ciência da informação. A seleção dos artigos foi realizada a partir de análises desenvolvidas em fase anterior da pesquisa, buscando a construção do objeto e do processo discursivos. As análises e discussões foram realizadas com base na Análise do Discurso da linha francesa. Considera que o discurso da interdisciplinaridade, na ciência da informação, é permeado por mais de uma formação discursiva, mas se encontra ancorado no discurso dominante, que tem como vetor as determinações do modo de desenvolvimento informacional. Esse discurso utiliza de estratégias naturalizantes e generalizantes para mascarar seu posicionamento ideológico. A fragilidade nos processos de integração disciplinar se traduz em dificuldade na constituição e consolidação epistemológica da ciência da informação.

\section{Palavras-chave}

Ciência da informação. Discurso da integração disciplinar. Epistemologia da ciência da informação. Epistemologia interdisciplinar.

\section{Disciplinary integration in information science: unsaid things about this familiar stranger}

\begin{abstract}
A considerable part of the epistemological studies in the field of Information Science, in Brazil, bears on a vector interdisciplinarity. However, some cases betray the difficulties of disciplinary integration and epistemological consolidation. These are based on construction of bibliometric indicators, excluding the discourse functions that reflect the sense effects arising there from. The objective of this paper is to understand the implicit and latent effects in the constitution of this discourse and the potential epistemological barriers to the consolidation of Information Science. The analytical corpus is based on 12 articles selected from the scientific Brazilian production which discuss the disciplinary integration in Information Science. Selection of the articles was based on an analysis developed in a previous phase of this research, seeking the construction of its object and discursive processes. The analysis and discussions were based on discourse analysis of French tradition. The discourse of interdisciplinarity, in information science, is permeated by more than one discursive formation, but is anchored by the dominant discourse which has as its vector the determinations of the informational development mode. This discourse uses naturalizing and generalizing strategies to mask its ideological contour. The fragility in the processes of disciplinary integration translates itself into a difficulty in the epistemological establishment and consolidation of Information Science.
\end{abstract}

\section{Keywords}

Discourse of Disciplinary. Epistemology of Information Science. Integration. Information Science. Interdisciplinary Espistemology. 
Esta "cobertura" lógica de regiões heterogêneas do real é um fenômeno bem mais maciço e sistemático para que possamos ver ai uma simples impostura construida na sua totalidade por algum Principe mistificador: tudo se passa como se, face a essa falsa-aparência de um real natural-social-histórico homogêneo coberto por uma rede de proposições lógicas, nenhuma pessoa tivesse o poder de escapar totalmente, mesmo, e talvez, sobretudo, aqueles que acreditam "não-simplórios": como se esta adesão de conjunto devesse, por imperiosas razões, vir a se realizar de um modo ou de outro (PÊCHEUX, 1990, p. 32).

\section{INTRODUÇÃO}

Os estudos epistemológicos constituem os fundamentos da compreensão e do desenvolvimento de um campo de conhecimento, e se encontram na base do processo de consolidação, uma vez que, conforme Rendón Rojas (2008), possibilitam seu autoconhecimento, sua autoconstrução e sua interdisciplinaridade. Para a ciência da informação, em particular, que além de ser um campo recente, tem na epistemologia interdisciplinar um de seus principais fundamentos, a necessidade desses estudos se apresenta de forma sublinhada. É preciso considerar, contudo, que haja o reconhecimento e, até mesmo, alguns destaques na literatura da importância deles; em contrapartida, há inegavelmente sua carência, principalmente daqueles que se dediquem aos aspectos teórico-metodológicos e às condições do desenvolvimento de uma epistemologia que os sustentem. Nessa perspectiva, faz-se necessário desenvolver estudos que deem cobertura a outros elementos que interferem mais ativamente na prática interdisciplinar e também na compreensão das implicações dela decorrentes.

A ausência ou a carência de estudos nessa perspectiva, na ciência da informação, denuncia que a epistemologia interdisciplinar se encontra atualmente baseada em referências pontuais e em indicadores, que são porém generalizados e que podem apontar para a necessidade de abarcar as várias facetas do objeto complexo informação; fundamentada num metadiscurso de integração dos saberes, tão cara à ciência contemporânea, em detrimento de construções epistemológicas direcionadas à construção de seu objeto de estudo e de seu campo de conhecimento específicos. A dinâmica da integração disciplinar no interior de um domínio de estudo, em direção ao processo de consolidação epistemológica, dá-se em dois movimentos convergentes de forças centrípetas e centrífugas, que promovem, ao mesmo tempo, a sua identidade disciplinar e sua participação em um movimento mais amplo de integração da ciência, considerando suas condições de produção amplas e restritas.

É preciso ainda considerar que, ao adotar a Análise do Discurso da linha francesa ${ }^{1}$ como dispositivo de análise, a ausência ou a baixa frequência de estudos epistemológicos que considerem suas condições de produção, longe de representar uma total ausência de sentido, possibilita um conjunto de efeitos de sentido que interferem na constituição e consolidação desse campo de conhecimento.

A prática científica é essencialmente uma prática social e, nesse sentido, é condicionada pelos modos de produção capitalista e de desenvolvimento atualmente vigentes. Considerando-se que este corresponde ao informacionalismo, o pensamento informacional tangencia as práticas nos diversos setores da sociedade, notadamente, técnicocientífico; ou, pelo menos, encontra-se nelas presentes.

\footnotetext{
1 A Análise do Discurso compreende que existe uma relação necessária entre o dizer e suas respectivas condições, colocando a exterioridade como marca fundamental deste. Nesse sentido, visa a explicitar e descrever montagens ou arranjos sócio-históricos de constelações de enunciados (PÊCHEUX, 1990). Os dispositivos teórico-metodológicos que balizam esse tipo de análise serão explicitados adiante.
} 
Este trabalho pretende, portanto, lançar um olhar sobre os efeitos de sentido do discurso da epistemologia interdisciplinar na produção científica da ciência da informação, partindo da materialidade de sequências discursivas (SD) selecionadas na produção científica brasileira, buscando abordar os não-ditos constituintes desse campo discursivo, a saber, os "implícitos" e os "silêncios". Assim, é necessário considerar preliminarmente que, segundo Pêcheux (2002, p. 45, apud FLORÊENCIO et al., 2009), o "discurso é um acontecimento que articula uma atualidade e uma rede de memória [....]. Todo discurso é índice de agitação nas filiações sócio-históricas". Além disso, apresenta os resultados parciais da segunda fase de uma pesquisa de doutoramento, que tem como objeto de estudo as implicações do discurso interdisciplinar no processo de consolidação epistemológica da ciência da informação.

Nesse intento, deve-se pois destacar a correlação entre a construção do conhecimento científico, o progresso da ciência, o sistema produtivo e o respectivo modo de desenvolvimento, com toda a carga de determinações sociais, políticas, econômicas e, de forma ampla, históricas e ideológicas. Não se trata, portanto, de ver o campo científico a partir de seus aspectos internos e externos, mas considerá-los como elementos indissociáveis e constitutivos, numa perspectiva contemporânea de cooperação epistemológica. As condições de origem e desenvolvimento da ciência da informação e, por conseguinte, de suas construções interdisciplinares são resultantes do processo histórico em que se encontram inseridas e fundamentadas, em um jogo de relações entre formações discursivas, que têm por base as respectivas formações ideológicas.

\section{SOCIEDADE DA INFORMAÇÃO E CIÊNCIA CONTEMPORÂNEA: CONTEXTOS DA INTEGRAÇÃO DISCIPLINAR}

A compreensão da constituição e do progresso do conhecimento científico, bem como de suas respectivas condições materiais, pode se dar, conforme Lyotard (2000), a partir de pelo menos dois entendimentos de sociedade que influenciam o funcionamento de seus diversos setores, nos aspectos econômicos, políticos, sociais e ideológicos: a concepção da sociedade como um todo funcional e a concepção da sociedade composta por duas partes que têm como base na luta de classes a dialética como fundamento da unidade social. Esses entendimentos condicionam e particularizam as bases teórico-metodológicas de estudos e pesquisas que procuram compreender as condições da prática científica.

Aliando-se à segunda concepção de sociedade e ao pensamento de Castells (2000, p. 33, grifo do autor), "a perspectiva teórica que fundamenta essa abordagem postula que as sociedades são organizadas em processos estruturados por relações historicamente determinadas de produção, experiência e poder". E ainda, que "as instituições sociais são constituídas para impor o cumprimento das relações de poder existentes em cada período histórico, inclusive os controles, limites e contratos sociais conseguidos nas lutas pelo poder" (CASTELLS, 2000, p. 33).

Além das relações determinadas naqueles três espaços, Castells (2000) destaca a importância da comunicação simbólica existente entre os humanos e entre eles e a natureza. Com base nos três elementos, os processos de comunicação simbólica se materializam ao longo da história em territórios específicos e assim constroem culturas e identidades coletivas.

A revolução informacional e a ciência contemporânea são, portanto, produto e processo do desenvolvimento técnico-científico que foi gestado em fins do século XIX e vem sendo ampliado, sobretudo a partir das duas últimas décadas do século XX. Além disso, esse processo é responsável pela constituição e manutenção do 
novo modo de desenvolvimento informacional ${ }^{2}$. De acordo com Castells (2000), porém, o fator histórico decisivo para essas transformações foi e continua sendo o processo de reestruturação do capital que se desenvolve desde a década de 1980, resultando num novo sistema econômico e tecnológico denominado capitalismo informacional.

Assim, no horizonte da compreensão da base material do processo integrativo característico da ciência contemporânea, é fundamental considerar que, nas palavras de Castells (2000, p. 35, grifo nosso):

Cada modo de desenvolvimento tem, também, um princípio de desempenho estruturalmente determinado que serve de base para a organização dos processos tecnológicos: o industrialismo é voltado para o crescimento da economia, isto é, para a maximização da produção; o informacionalismo visa o desenvolvimento tecnológico, ou seja, a acumulação de conhecimentos e maiores niveis de complexidade do processo informacional. Embora graus mais altos de conhecimentos geralmente possam resultar em melhores níveis de produção por unidade de insumos, é a busca por conhecimentos e informação que caracteriza a função da produção tecnológica no informacionalismo.

Nesse contexto, dentre uma série de características do novo modelo de desenvolvimento, é imperativo destacar que a marca da atual revolução tecnológica concerne a não centralidade do conhecimento e da informação, uma vez que o foco se encontra na aplicação desses conhecimentos e informações num processo dinâmico de geração de conhecimentos e

\footnotetext{
2 A história da sociedade é composta por três modos de desenvolvimento: o agrário, o industrial e o informacional. O modo de desenvolvimento agrário foi caracterizado pela adoção de quantitativos de mão de obra e de recursos naturais. O modo de desenvolvimento industrial teve como principais elementos de produtividade a utilização das novas fontes de energia e a capacidade de descentralização do uso de energia. $O$ atual modo de desenvolvimento informacional se caracteriza pelo uso das tecnologias de informação na geração de conhecimento, no tratamento da informação e no processo de comunicação (CASTELLS, 2000).
}

dispositivos de processamento e comunicação da informação, formando um ciclo cumulativo entre a inovação e o uso (CASTELLS, 2000). O fato é que o modelo de desenvolvimento informacional depende dos fluxos de informação e da renovação do processo de conhecimento, no contínuo movimento em que são realizados a partir do uso das novas tecnologias de informação e comunicação.

Na esfera científica, a partir de fins do século XIX, começa a se esboçar no mundo ocidental um novo modelo de cientificidade, que no início do século XX resultaria nas bases da atual ciência contemporânea. Esse modelo, segundo Santos (2003), é caracterizado pelo reconhecimento da complexidade da natureza, da relação sujeito-objeto e da insuficiência do modelo de analiticidade moderno diante daquela constatação. A ciência contemporânea é resultado de dois movimentos convergentes: a insatisfação com o modelo de analiticidade, que vinha sendo desenvolvido no interior da ciência moderna, caracterizado, sobretudo, pelo esfacelamento do objeto, e a segmentação da ciência em áreas e/ou campo do conhecimento cada vez mais especializado. A prática científica contemporânea representa não somente uma nova forma de estudar e compreender a natureza, mas essencialmente o estabelecimento de novas relações políticas, econômicas e sociais, e, consequentemente, científicas sedimentadas no capital informacional.

É preciso considerar, mais do que nunca, que a prática científica e o progresso do conhecimento seguem a lógica do modo de produção capitalista, mergulhados num ambiente globalizante interligado por redes, fundamentados nas novas tecnologias de informação e comunicação, mas centrados no fluxo de informação e conhecimento que, em última análise, possibilitam a inovação e a competitividade no sistema produtivo. Assim, considera que, para além de questões epistemológicas, o alargamento das fronteiras em diversos campos do conhecimento, conforme destacaram Domingues (2004) e Pombo (2003), tem por base os princípios do modo de 
desenvolvimento informacional, que visa, segundo Castells (2000), à acumulação de conbecimento e à obtenção da complexidade do processo informacional. Considera-se ainda que este estado de coisa se faz mais presente nos campos e/ou áreas científicos que têm a informação e o conhecimento como objetos de estudo.

Dessa forma, a ordem científica estruturada no atual modelo de produção capitalista fundamenta-se no modelo de globalização do capital, assumindo suas condições a partir da perspectiva de rede que significa glocalizar. Na prática científica, a nova configuração vem sendo perseguida a partir da integração disciplinar, que tem na transdiciplinaridade seu maior projeto.

Assim como a globalização, no campo científico o projeto transdisciplinar

[...] remete a processos de conhecimento que concebem a fronteira como espaço de trocas e não como barreira, processos que incitam à migração de conceitos, à frequentação exploratória de outros territórios, ao diálogo modificador com o diverso e o de outra forma, processos que não se esgotam na partição de um mesmo objeto entre disciplinas diferentes, prisioneiras de pontos de vista singulares, irredutíveis, estanques, incomunicados (SILVA, 2004, p. 36-37).

A produção científica realizada nesse espaço se coloca num movimento de alargamento crescente da área ou campo de conhecimento que, tal como o aprofundamento especializado, constitui-se, segundo Domingues (2004), em obstáculo epistemológico ${ }^{3}$, notadamente, ao processo de consolidação epistemológica. A prática da integração disciplinar, principalmente a interdisciplinaridade, que se localiza nas proximidades do ponto transdisciplinar, deve ser

\footnotetext{
3 Obstáculos epistemológicos correspondem aos entraves ao progresso do conhecimento científico, que promovem a inércia ou a regressão do pensamento científico (BACHELARD, 1996).
}

objeto de constante vigilância epistemológica ${ }^{4}$, uma vez que se encontra no ponto de conflito existente e ainda não resolvido '[...] entre 'o generalista' (que se esforça para alargar e unificar o conhecimento) e o 'especialista' (que se esforça por aprofundá-lo)" (DOMINGUES, 2004, p. 14).

O processo de consolidação epistemológica ou de autonomia do campo, segundo Bourdieu (1983), implica, ao mesmo tempo, a integração dos elementos constituintes do campo e o estabelecimento de relações com áreas e/ou campos do conhecimento circunvizinhos, considerando os diversos contextos em que essas relações se realizam.

As condições amplas de produção da prática científica da ciência da informação se inserem na nova ordem técnico-científica. De um lado, a superação do modelo de desenvolvimento industrial e do outro, mas como parte integrante daquele, a correspondente superação do modelo de analiticidade construído e estabelecido durante toda a era moderna. A palavra de ordem nesta nova fase do capitalismo e, portanto, da ciência, é complexificar, que em termos teórico-metodológicos significa re-ligar, buscar as múltiplas facetas que compõem os objetos de estudo da ciência (MORIN, 2007). Numa vertente político-econômica, a nova ordem se sustenta, respectivamente, na política neoliberal e na globalização dos mercados (CASTELLS, 2000), ao passo que, na esfera científica, fundamenta-se em uma nova topa de conhecimento reticular (DOMINGUES, 2005), baseada na integração dos saberes. Esse contexto amplo referencia todo o desenvolvimento da ciência da informação, que procura corresponder às exigências do mercado capitalista e atender às demandas ou às necessidades sociais do período em que foi criada aos dias atuais.

\footnotetext{
${ }^{4}$ A vigilância epistemológica, segundo Bachelard (1977), refere-se a um posicionamento crítico do pesquisador diante do objeto de estudo e dos problemas de pesquisa por ele construídos.
} 


\section{CONDIÇÕES EPISTEMOLÓGICAS DA CIÊNCIA DA INFORMAÇÃO: DA ORIGEM MULTIDISCIPLINAR À CONSOLIDAÇÃO (INTER)DISCIPLINAR}

A compreensão da constituição e do desenvolvimento do campo da ciência da informação bem como do contexto em que surgem esses movimentos se apresenta como indispensável ao entendimento da construção de seu objeto de estudo, da organização de sua comunidade cientifica, da prática científica desenvolvida no seu interior e da constituição de seu domínio epistemológico. Nesse sentido, existe extensa produção científica internacional e nacional dispersa e, ao mesmo tempo, vinculada a diversos pesquisadores, publicações e instituições.

Nascida sob a influência da Revolução Informacional, na segunda metade do século XX, a ciência da informação é, de acordo com Le Coadic (1996), resultado da valorização convergente da informação por três setores da sociedade: a indústria da informação, a tecnologia da informação e o campo científico. Nesse sentido, resultante de esforços conjuntos de diversas áreas e profissionais a elas ligados, esse campo de conhecimento nasce no epicentro dos principais elementos constituintes do novo modelo de desenvolvimento.

Esse contexto associado a diversos fatores, tais como múltiplas necessidades de informação; diversas áreas interessadas nos processos de informação e com ele já envolvidas naquele período; e atuação de profissionais de diferentes formaçôes técnico-científicas, constituíram as condições para a conformação de um campo de conhecimento de difícil organização e compreensão, mas tão logo reconhecido como interdisciplinar.

Ao longo de sua recente história epistemológica, o conceito amplo que fez parte da institucionalização da ciência da informação parece acompanhar os períodos de sua evolução:

[...] disciplina que investiga as propriedades e o comportamento da informação, as forças que governam seu fluxo e os meios de processamento para otimizar sua acessibilidade e utilização. Relaciona-se com o corpo de conhecimentos relativo à produção, coleta, organização, armazenagem, recuperação, interpretação, transmissão, transformação e utilização da informação (BORKO, 1968, p. 3).

O entendimento amplo do campo da ciência da informação vem possibilitando diversas leituras e, consequentemente, diferenciadas construções em torno do objeto de estudo, do campo profissional, dos profissionais da informação e, sobretudo, de relações interdisciplinares. Entretanto, parece não ter contribuído de forma significativa para a definição do domínio epistemológico, que corresponde à base de todas aquelas definições. O conceito de Borko (1968) pode ser considerado amplo, mas constitui um projeto eficiente para o desenvolvimento epistemológico da ciência da informação. Há grande possibilidade de os conceitos posteriormente desenvolvidos se localizarem no seu todo, ou em alguma parte daquele. O problema é que algumas leituras sobre Borko (1968) consideram o conceito na sua completude, no entanto, focam na segunda parte deste. Insiste-se aqui que, para o desenvolvimento do domínio epistemológico, isso representa um entrave, uma vez que as propriedadesprincipalmente elas - e o comportamento da informação, e as forças que governam sen fluxo correspondem, pelo menos neste momento, àquilo que mais se aproxima do vetor de integração epistemológica da ciência da informação. Ele possibilita, ao mesmo tempo, a integração de seus elementos internos e os desdobramentos de relações interdisciplinares. Esses últimos, principalmente, a partir das construções teórico-metodológicas em torno do conjunto de processos que compõem a segunda parte do conceito de Borko (1968).

Considerando porém o contexto e os problemas que vêm orientando o desenvolvimento da ciência da informação, pode-se observar que a sua prática interdisciplinar se aproxima daquilo que Domingues et al. (2004) denominaram vício de origem, ou seja, 
trata-se mais de um compartilhamento de objeto de estudo ou de alguns aspectos deste, mas segundo pontos de vista diferentes, por diversos campos e/ou áreas do conhecimento, tais como biblioteconomia, documentação, recuperação da informação, comunicação, entre outros.

Para balizar a postura epistemológica vigilante necessária, algumas constatações feitas na literatura especializada, no que concerne ao objeto de estudo, ao dominio epistemológico e às relações interdisciplinares, devem ser mencionadas e refletidas. Apesar de a ciência da informação se encontrar na fase de consolidação epistemológica e de aprofundamento das relações interdisciplinares (PINHEIRO, 2005), “[...] ninguém aceita 'informação' como objeto porque ninguém sabe o que ela é (se alguém sabe parece ser um tema de alguma disciplina já existente). Ela [ciência da informação] não poderia desenvolver um método específico por causa da obscuridade do suposto objeto." (WERSIG, 1992, p. 210). Segundo González de Gómez (2000, grifo da autora),

A pesquisa em ciência da informação apresentaria um problema particular que podemos identificar de modo quase imediato: Se existe grande diversidade na definição das heurísticas afirmativas, as que definem as estratégias metodológicas de construção do objeto e que permitem a estabilização acumulativa do domínio, maior é a dificuldade para estabelecer as heurísticas negativas, as que definem o que não poderia ser considerado objeto do conhecimento da ciência da informação, condição diferencial que facilita e propicia as relações de reconhecimento e complementaridade com outras disciplinas. E isto acontece na ciência da informação por um lado, pela referência intrínseca de seu objeto a todos os outros modos de produção de saberes, gerando constantemente novas treliças interdiscursivas, e por outro lado, pela natureza estratificada e poliepistemológica dos fenômenos ou processos de informação.

Além disso, a ciência da informação apresenta ritmos de desenvolvimento diferenciados entre teoria e prática, e, por vezes, desvinculação entre elas (LE COADIC, 1996). No que concerne ao campo, ele é pouco desenvolvido no interior e muito povoado nas encostas (WHITE; MCCAIN, 1998). As relações interdisciplinares com a biblioteconomia, que é apontada ao lado da administração como fonte de maior exercício dessa prática (PINHEIRO, 2005), segundo Dias (2000), não possuem bases sólidas. Fechando o quadro, após alguns anos de discussão sobre a origem, a evolução e as relações interdisciplinares da ciência da informação (SARACEVIC, 1992, 1995, 1996, 1999), Saracevic (2009) destaca a dificuldade de integração dos elementos internos que compõem o campo.

Considerando a recente história da ciência da informação e as observações realizadas num período de pelo menos dez anos, por pesquisadores de diversas partes do mundo, parece necessário encontrar um fio condutor para algumas discussões. Há pelo menos duas possibilidades: os pesquisadores que estão ingressando no campo não estão fazendo os necessários movimentos de interiorização e integração, ou os que aí já estão, numa ânsia interdisciplinar, esquecem de interligar os nós que constituem a rede de seu campo.

De modo geral, a comunidade científica corresponde ao grupo de profissionais que se dedicam à pesquisa científica e tecnológica (LE COADIC, 1996). No campo da ciência da informação, ela se compõe, desde sua origem, de um conjunto de profissionais originários de diferentes áreas do conhecimento, dentre eles administradores, bibliotecários, cientistas da computação, documentalistas, engenheiros e tecnólogos, que vêm se dedicando aos estudos, pesquisas e atividades relacionados à informação, seus processos e suas tecnologias. A multiplicidade da formação básica dos profissionais que constituem essa comunidade é uma característica que interfere diretamente nas suas produções e, portanto, deve ser considerada nas questões do domínio epistemológico do campo. 
Além da diversidade de especialistas que compõem a comunidade científica da ciência da informação no Brasil e em vários países, o seu campo de conhecimento, a construção de seu objeto de estudo e o modelo contemporâneo de desenvolvimento científico correspondem a um conjunto de elementos que condicionam a sua prática científica. Alguns autores, a exemplo de Le Coadic (1996, p. 56), entendem que, em que pese a esse conjunto de condições de desenvolvimento, "pouco a pouco, foram sendo elaborados conceitos, métodos, leis e teorias próprios dessa nova ciência".

Se no entendimento desse autor o objeto de estudo e os problemas fundamentais de pesquisa, cujas composições se dão na correlação com o respectivo arcabouço teórico-metodológico, foram suficientemente delimitados, esse processo se deu, grosso modo, num apanhado de conceitos, métodos, leis e teorias advindos de outras áreas ou campos de conhecimento que também têm no campo amplo da informação seus problemas e objetos de pesquisa, tais como aqueles por ele citados: biblioteconomia, museoconomia, documentação, jornalismo, informática, psicologia, sociologia, ciências cognitivas e comunicação. Embora não se possa elencar e muito menos discutir todos aqui, é importante citar alguns a título de ilustração. No conjunto de "conceitos próprios" dessa nova ciência, Le Coadic (1996) menciona alguns científicos (descrição de dados, manipulação de dados, gerenciamento de transações, controle de fila, citação, hipertexto, obsolência e classificação) e técnicos (referências, tesauro e catálogo). No que concerne aos métodos, o autor cita os conhecidos métodos de catalogação, indexação, elaboração de resumos e clustering; e outros derivados, como a análise de cocitação e análise de termos associados.

Ainda no exercício de destacar as construções próprias da ciência da informação, Le Coadic (1996), ressaltando sua característica nomotética, cita as leis bibliométricas e as leis epidemiológicas. Os modelos do campo são sintetizados nos processos de comunicação e recuperação da informação (vetorial, probabilístico e linguístico). Concluindo, o autor destaca que

a ciência da informação não possui ainda, lamentavelmente, uma teoria ou conjunto de teorias que permita interpretar de forma científica, racional, essas leis e esses modelos empíricos. Em matéria de informação, a prática precedeu a teoria. A teoria corre atrás dos fatos para compreendê-los. A teoria está atrasada em relação ao empírico e, sobretudo, há desconexão entre os dois (LE COADIC, 1996, p.76-77).

Mesmo assim, o autor aponta três abordagens teóricas que dizem respeito à informação - a teoria matemática da informação, a teoria dos meios de comunicaşão de massa e a teoria da comunicação interativa.

Pode-se acrescentar a essa lista outras leis e teorias citadas e ligeiramente descritas na literatura especializada, umas mais gerais, outras mais específicas, umas mais próximas, outras mais distantes, tais como as Leis de Ranganathan, a Teoria de Sistemas, a Teoria Crítica da Informação e as Teorias da Classificação e Representação (filosóficas, bibliográficas e/ou documentárias) (ARAÚJO, 2009). Longe de defender qualquer movimento de enclausuramento de objeto, pesquisador, problema ou campo científico em um conjunto de teorias e leis inequívocas, compreende-se a necessidade de algumas démarches que orientem a produção do campo.

As necessárias e devidas importações de conceitos, métodos, teorias e leis de outras ciências, áreas e campos do conhecimento correspondem à importante fonte da prática do conhecimento, principalmente se considerar a abertura e a sua correlata integração disciplinar na ciência contemporânea; contudo, é uma porta aberta às práticas ligeiras que não são frutíferas ao processo de consolidação. Brandão (2005) discute as práticas de importação e de tradução de conceitos em perspectivas transdisciplinares, que se caracterizam 
pela dificuldade do rigor metodológico em função do movimento de expansão, da inexistência de limites precisos e de objetos claramente configuráveis e passíveis de serem visados.

Além da importação de conceitos sem a devida fundamentação teórico-conceitual, faz-se necessário observar as características dos métodos e das técnicas de pesquisa utilizados no campo. Aqui duas questões merecem atenção. A flutuação teórico-metodológica é uma porta aberta aos estudos exploratórios e descritivos, que têm sua relevância e devido lugar na produção científica, mas que carecem serem aprofundados no âmbito dos outros dois níveis metodológicos apontados por Domingues (2004), isto é, da explicação e da interpretação.

O pluralismo epistemológico decorre da contínua e crescente importação de conceitos de outras ciências ou campos de conhecimento, muitas vezes sem os devidos processos de tradução. Além disso, é preciso lembrar e considerar que os critérios epistemológicos de escolhas e utilização de determinados conceitos, teorias e metodologias, que compõem e/ou comporão o seu domínio, têm por base não o conjunto desses elementos enquanto tal, mas o que se diz ou se pode dizer - e em que condições - sobre aqueles elementos na construção do seu domínio. Nesse sentido, a epistemologia define suas bases analíticas, mas embora numa proposta não nomotética, define também certo nível normativo que possibilita, pelo menos, alguns compromissos teórico-metodológicos e, em última análise, a comunicação entre os pesquisadores.

Observa-se, a partir de Le Coadic (1996), certa evolução nos estudos por ele denominada paradigmática, ao apresentar os "paradigmas" antigos (trabalho individual, acervo, orientado para Bibliotecário e papel) e novos (trabalho coletivo, fuxo, orientado para usuário e elétron) da ciência da informação. Em Capurro (2003), os estudos do campo são organizados em três "paradigmas" complementares (fisico, cognitivo e social). Sem adentrar na discussão sobre a aplicação desses conceitos desenvolvidos por Kuhn (2007), no campo da ciência da informação, mesmo quando se considera a mudança de paradigmas, conforme Le Coadic (1996), pode-se observar a contínua utilização dos conceitos e teorias do paradigma anterior. Esse ponto parece ser um significativo horizonte para a compreensão dos princípios que regem a difícil integração disciplinar na ciência da informação.

A necessidade da integração disciplinar na ciência da informação aponta para o desenvolvimento de pesquisas e práticas consilientes na relação com o conjunto de áreas ou ciências que trabalham com a informação. Embora outras ciências ou disciplinas atuem de forma indireta com a informação e, por isso, possuam um estatuto "periférico" do fenômeno informacional, é dever dos pesquisadores delas originários fazer movimentos de deslocamento e aproximação do conjunto integrado do campo da ciência da informação e, a partir daí, estabelecerem relações com suas respectivas áreas de origem.

\section{DISPOSITIVOS TEÓRICO-ANALÍTICOS: DA CONSTITUIÇÃO DO CORPUS À ANÁLISE DOS DISCURSOS}

A análise do discurso se processa a partir da composição de um dispositivo de interpretação que implica a correlação entre um referencial teórico e os procedimentos de análise, ou seja, a construção do lugar da interpretação. Dessa forma, esse dispositivo tem como característica desenvolver nova práticasde leitura que "[...] consiste, como se sabe, em multiplicar as relações entre o que é dito aqui (em tal lugar), e dito assim e não de outro jeito, com o que é dito em outro lugar e de outro modo, a fim de se colocar em posição de 'entender' a presença de não-ditos no interior do que é dito" (PÊCHEUX, 1990, p. 44).

Partir do dito ao não-dito significa, segundo Orlandi (2001), considerar as pistas e os vestígios naquele inscritos, que, em sendo marcas formais para o 
analista, só interessam na relação destes com a materialidade discursiva, que promove a relação entre língua e história, ou seja, a relação línguaexterioridade. Nesse movimento, utilizam-se os implícitos e os silenciamentos como fios condutores da compreensão do processo discursivo. De acordo com Ducrot (1972, apud ORLANDI, 1992 , 2001), distinguem-se duas formas de não-dito: o pressuposto e o subentendido. Aquele deriva propriamente da instância da linguagem, estando necessariamente presente no dito. Este, por sua vez, que caracteriza o silêncio, deriva do contexto, não podendo ser necessariamente relacionado ao dito.

Nesse sentido, algumas noções possibilitam um movimento na compreensão do não-dizer, quais sejam, condições de produção, formação ideológica, interdiscurso e formação discursiva. As condições de produção correspondem ao conjunto de elementos estruturais que engendram os discursos e se classificam em amplas e restritas. As primeiras expressam a relação do discurso com o contexto sócio-histórico-ideológico, ao passo que estas correspondem às condições imediatas que possibilitam o acontecimento discursivo. As formações ideológicas se referem a um conjunto de atitudes e representações de caráter regional que concerne às posições de classe em um conflito. Caracterizado por uma reconfiguração constante, o interdiscurso corresponde à relação entre os sentidos anteriormente constituídos e uma formulação atual. Este constitui o espaço do préconstruído (FLORÊNCIO et al, 2009). A formação discursiva, por sua vez, define aquilo que, numa formação ideológica dada, determina o que pode ser dito (ORLANDI, 2001).

Para composição do dispositivo de análise da cadeia conceitual da integração disciplinar, foram mapeados os artigos publicados no período de 1990 a 2008, nos seguintes periódicos científicos: ciência da informação, Data Grama Zero - Revista de ciência da informação, Encontros Bibli - Revista Eletrônica de Biblioteconomia e ciência da informação, Informação e
Sociedade: estudos, Perspectivas em ciência da informação e Transinformação. De um total de 2083 (dois mil e oitenta e três) artigos mapeados, 669 (seiscentos e sessenta e nove) veiculam enunciados sobre aquela rede conceitual e destes apenas 28 (vinte e oito) artigos a têm como objeto central de discussão. Sua constituição teve como base as orientações de Orlandi (2001), ou seja, o problema da pesquisa, a natureza do material a ser analisado e as probabilidades de análise.

O corpus analítico resultou da centralidade do discurso interdisciplinar, ou seja, da combinação entre temática dos artigos e os indicadores de produtividade de seus respectivos autores. Com efeito, este foi composto por 12 (doze) artigos que versam sobre a cadeia conceitual da integração disciplinar cujos autores tiveram índices de produtividade entre 14 (quatorze) e 7 (sete) artigos: Isa Maria Freire - 14 (quatorze), Maria Nélida González de Gómez - 12 (doze), Nair Yumiko Kobashi - 9 (nove), Maria das Graças Targino - 8 (oito) e Lena Vânia Ribeiro Pinheiro 7 (sete) artigos (Apêndice A).

As análises desenvolvidas a partir destes indicadores da materialidade discursiva possibilitaram, conforme destaca Orlandi (2001), a constituição do objeto de-superficializado, a partir das mobilizações das noções e dos dispositivos teóricos, na perspectiva da definição do dispositivo analítico. Esses dados não são considerados meras ilustrações, mas como fatos da linguagem com sua memória, sua espessura semântica, sua materialidade-discursiva.

Nos procedimentos de análise do discurso, foram adotadas ainda as orientações amplas de Orlandi (2001), procurando remeter os textos ao discurso e esclarecer as relações deste com as formações discursivas, e as relações destas com a ideologia. Assim, foi analisado o objeto discursivo, procurando estabelecer os processos discursivos e a constituição do sujeito do discurso nas relações entre formações discursivas e formações ideológicas, independente 
da autoria dos textos que compõem a base material. Além disso, as SD foram sistematizadas e expressas em formato alfanumérico, como, por exemplo, a SD 1.10.8 (recorte 1, artigo 10 e SD 8), que também pode ser lida da seguinte forma: a SD 8 (oito) do artigo 10 (dez) que compõe o conjunto de artigos do recorte 1 (um).

\section{A INTEGRAÇÃO DISCIPLINAR NA CIÊNCIA DA INFORMAÇÃO ENTRE IMPLÍCITOS E SILENCIAMENTOS: APROXIMAÇÕES ANALÍTICAS}

A construção do lugar de interpretação permite, num primeiro momento, perceber que não existe um discurso mas um processo discursivo, constituído por uma multiplicidade de discursos que se relacionam entre si e com a memória discursiva, em um processo interdiscursivo constante, seja reiterando, discordando ou polemizando. Do ponto de vista epistemológico, pode-se dizer que a interdisciplinaridade se constitui atualmente no instrumento teórico-metodológico mais próximo da integração interna e externa dos campos científicos. Em uma primeira aproximação com a materialidade discursiva, considerando os ditos das $\mathrm{SD}$, a interdisciplinaridade assume esse sentido em maior ou menor grau. As SD sobre a integração disciplinar da/na ciência da informação, no Brasil e no mundo, têm como base o novo modo de fazer ciência (DOMINGUES, 2004; SANTOS, 2003), a nova topologia da sociedade e novo modelo de desenvolvimento capitalista (CASTELLS, 2000).

Contudo, a partir de Pêcheux (1990), pode-se considerar que essa aparente constatação é explicitada a partir de uma rede de proposições lógicas, tanto positivas ("o objeto é complexo, então o conhecimento é necessariamente interdisciplinar"; "a ciência da informação tem sua origem a partir de diversas disciplinas, resultando num campo interdisciplinar"; e "a comunidade científica da ciência da informação é constituída por profissionais de diversas áreas, que promovem a prática interdisciplinar"), e disjuntivas ("ciência moderna versus ciência contemporânea" e "conhecimento disciplinar versus conhecimento interdisciplinar"). Apesar da multiplicidade existente entre eles, trata-se de espaços controlados e o que os liga são as evidências lógico-práticas. Alguns enunciados ilustram esses arranjos que representam grandes deslocamentos no discurso interdisciplinar como, por exemplo, a $S D$ 1.11.3: "a passagem da modernidade para a pós-modernidade, ou mais especificamente da disciplinarização do conbecimento para a sua interdisciplinaridade, foi tão rápida e intensa, que diversos domínios, dentre os quais o da ciência da informação, estabeleceram-se pontualmente, em sincronia, não tendo empreendido a reflexão sobre o próprio trajeto de sua constituição".

De outro ângulo, saindo dos pontos de estabilização dos enunciados, conforme sugere Pêcheux (1990), pode-se observar que a estabilidade é atravessada por uma série de "marcas de distância discursiva", que aqui vêm à tona a partir dos implícitos constatados na materialidade discursiva. Ademais, os silenciamentos promovem outros efeitos que, ao serem analisados, desestabilizam ainda mais aquela suposta ordem discursiva. O fato é que, segundo a $S D$ 1.7.2, “[...] sob a égide da interdisciplinaridade, o campo da informação se vê refletido em quadros teóricos de campos de conhecimento institucionalizados, submetendo-se à imposição de critérios disciplinares estranhos e nem sempre adequados aos seus objetivos específicos".

A primeira observação é que o discurso da interdisciplinaridade na ciência da informação é atravessado por uma rede interdiscursiva que traz as marcas dos discursos da política neoliberal e do processo de globalização da economia. Esses discursos, por sua vez, encontram força na estrutura topológica sustentada pelo novo modelo de desenvolvimento capitalista, o informacionalismo. Embora se refira a um espaço científico heterogêneo caracterizado pela constante tensão, disputa e negociação, o discurso interdisciplinar é construído a partir de constatações lógicas aparentemente 
homogêneas: $S D$ 1.8.3 "[...] a ciência da informação se define, como outros campos de conbecimento, pelos problemas a que se dedica e pelos métodos que utiliza para solucioná-los. Três são as suas características fundamentais: a interdisciplinaridade, sua relação necessária com as tecnologias da informação e o seu papel na constituição da sociedade da informação". A nova ordem do mercado é interligar, que, na perspectiva hegemônica, significa a construção de redes articuladas a partir de centros de poder de informação e conhecimento. Embora a formação ideológica procure camuflar os conflitos presentes nessa ordem topológica, passando a ideia de relação direta entre centro e periferia, em outros termos, a ausência de classes, o discurso interdisciplinar aflora toda essa tensão.

A interdisciplinaridade se constitui em um espaço que o mercado encontrou, no campo científico, para, por intermédio de um jogo ideológico, manter o seu domínio sobre a produção e a circulação do conhecimento. Em uma perspectiva de rede e em horizonte que se apresenta aparentemente como um movimento transdisciplinar inocente ou despido de um posicionamento ideológico, "a interdisciplinaridade a serviço desse jogo" liga e desliga os campos conforme as ordens do capital. SD 1.1.1: "Esta nova ciência tem sido caracterizada, desde os primórdios, por uma abordagem interdisciplinar de problemas e uma visão social da informação, o que permite propor como responsabilidade social do novo campo: facilitar a comunicasaão do conbecimento científico".

É oportuno ainda destacar que, ao se colocar nessa esfera, a ciência da informação é convocada a se desenvolver a partir de uma perspectiva que se coloque a serviço da nova ordem. Dessa forma, tem como efeito de sentido uma errante integração externa, em uma ótica da formação ideológica capitalista, que ganha forma em um discurso autoritário, apelando para várias estratégias discursivas, notadamente, para a naturalização e a generalização dos processos. Além disso, recorre aos espaços aparentemente estabilizados, como pode ser ilustrado com a $S D$ 1.10.8 - "A existência e necessidade da informação para quase todas as profissões, ciências e culturas [...]". Esse generalismo corresponde à outra estratégia discursiva utilizada na ligação dos espaços aparentemente estabilizados do discurso da interdisciplinaridade na ciência da informação. De forma ampla, esse discurso encontra repouso em um metadiscurso da ciência contemporânea. Assim, "[...] em qualquer circunstância, a informação atua como instrumento propulsor do desenvolvimento dos vários ramos do conbecimento bumano, das nações e povos. E mais do que isto. Aflora como elemento de unificação das relacõoes inter e transdisciplinares da CI" (SD 1.12.2). É preciso não perder de vista que esse arranjo discursivo não observa as particularidades da informação como objeto de estudo de uma ciência específica, desconsiderando o processo de construção do objeto científico com suas definições teóricometodológicas.

A marca do apagamento das diferenças é característica do discurso autoritário da interdisciplinaridade: $S D$ 1.12.1 - "[...] como resultante do seu próprio objeto de estudo - a informação - presente em todas as áreas do conbecimento bumano, a CI assume caráter interdisciplinar e transdisciplinar" e $S D$ 1.2.2 "[...] trocas significantes estão acontecendo entre vários campos científicos que abordam os mesmos problemas de informação, ou semelhantes, de formas bastante diferentes [a] ciência da informação definitivamente deveria unir esses campos".

A complexidade corresponde a outro ponto de estabilidade no discurso da interdisciplinaridade na ciência da informação, tanto no que concerne ao objeto de estudo quanto ao sujeito conhecedor, como destaca a $S D$ 1.10.7 - "[...] a complexidade e multidimensionalidade do sujeito da ciência da informação [...]". A pluralidade epistemológica apontada por autores como Tálamo e Smit (2007) é resultante da flutuação das inter-relações construídas conforme a necessidade exterior, em detrimento de 
um processo de integração disciplinar orientado à construção da autonomia do campo.

Os processos discursivos cujas formações se instalam no discurso polêmico deixam escapar, contudo, a relação tensa que se estabelece na disputa dos sentidos. Nesse espaço, por desvincular mais das determinações do mercado, a interdisciplinaridade assume igualmente o sentido de integração disciplinar, marcado pelo conflito e pela negociação, em uma perspectiva crítica. Esses processos, ao contrário daqueles ancorados na formação ideológica do capital, segundo Orlandi (2001), apresentam conflitos e tensões que evidenciam as disputas de sentido, conforme ilustra a $S D$ 1.11.1: "[...] associa a propalada interdisciplinaridade a uma reunião de diferentes disciplinas, revelando uma inconsistência teórica, associando a área a um abordagem a-bistórica". E de forma mais acentuada no enunciado da $S D$ 1.8.5: "A abordagem do seu objeto é interdisciplinar já que esta é uma exigência das temáticas que trata, mas a ciência da informação enquanto tal constitui campo específico - uma disciplina".

Uma questão a ser observada nos discursos analisados diz respeito aos efeitos de sentido na relação entre interdisciplinaridade e disciplina. Esse efeito é variado, conforme a relação com os sentidos, a relação entre os sujeitos e a relação com o referente discursivo (ORLANDI, 2001). A relação entre interdisciplinaridade e disciplina está além das denominações aparentes. A disciplina, no discurso interdisciplinar polêmico, não tem o efeito de sentido de determinação de fronteiras, de esfacelamento ou desfragmentação do saber, mas se apresenta como elemento constitutivo da dinâmica interdisciplinar. A interdisciplinaridade tem como referência a disciplina e, portanto, coloca-se naquela tensão existente entre os movimentos de identificação e diferenciação: $S D$ 1.11.2 “[...] seja qual for a denominação a ela atribuída [a ciência da informação], afirmou-se na interdisciplinaridade [...] sem examinar com clareza sua própria trajetória disciplinar autônoma". No processo discursivo dominante, contudo, a disciplina assume um efeito de sentido de pensamento retrógrado que circunscreve no pensamento moderno e, ao mesmo tempo, pode trazer o efeito de demarcação de espaço, por isso, aproxima-se dos silêncios estabelecidos em uma política discursiva, desenvolvendo-se em uma contínua rede interdiscursiva com fundamentos no discurso político neoliberal.

A diversidade de formação dos profissionais envolvidos na composição do campo científico da ciência da informação é também utilizada como ponto de estabilidade dos arranjos discursivos. Pode se observar uma sequência lógica da interdisciplinaridade nas SD seguintes, que produzem um efeito de sentido lógico-prático nas condições e na prática efetiva da interdisciplinaridade, ou seja, a existência de diferentes disciplinas e profissionais de diferentes formações. Dessa forma, a SD 1.2.5 "Característica interdisciplinar da CI: [...] as contribuições para o nascimento da 'ciência da informação' vieram de muitas disciplinas diferentes (devido às experiências diferentes das pessoas que atuam em um campo onde não existia nenhum sistema educacional estabelecido) e sua emergência foi causada por muitos interesses diferentes (devido a áreas diferentes de aplicação envolvidas no trabalho de informação)". Além disso, "[...] a característica de abordagem orientada para um problema, reunindo cientistas e técnicos de diversas áreas envolvidos em sua solução, no que poderia se traduzir em uma visão interdisciplinar sobre uma dada situação" (SD 1.1.4).

Desse conjunto de arranjos discursivo, evidenciase que "a característica interdisciplinar da ciência da informação não precisa ser procurada, está lá, no âmago do próprio campo científico" (SD 1.3.2). Há, porém, uma formação discursiva em que se inscreve o entendimento de que "o lócus do encontro interdisciplinar é o problema. E não devemos confundir as coisas. Uma situação interdisciplinar, não importa quanto seja familiar, permanece indeterminada... até que se estabeleça uma relação de equivalência entre os termos do encontro disciplinar [...]" (SD 1.6.5). 


\section{CONSIDERAÇÕES FINAIS}

A integração disciplinar tem atualmente na interdisciplinaridade o seu principal instrumento teórico-metodológico, uma vez que, embora a ciência contemporânea tenha como proposta $\mathrm{O}$ desenvolvimento de estudos transdisciplinares, ela se constitui na prática exequível de integração dos elementos internos e externos dos campos de conhecimento específicos. Nesse contexto, a ciência da informação, desde a sua origem na segunda metade do século XX, vem adotando a interdisciplinaridade como um de seus pressupostos. Contudo, ao mesmo tempo em que a assume, apresenta algumas dificuldades na identificação e na definição de suas práticas científicas.

A interdisciplinaridade é assumida como espaço logicamente estabilizado, no discurso da ciência da informação; no entanto, uma questão nãodita expressamente nas discussões sobre a interdisciplinaridade, em particular, e a integração disciplinar, de forma ampla, diz respeito ao campo de lutas e forças que as constituem, com toda a carga de determinações sociais, políticas, econômicas e, notadamente, ideológicas. As lutas travadas no campo científico evidenciam as lutas de classes que constituem a sociedade capitalista contemporânea e existem em função dos compromissos teórico-metodológicos que originam e caracterizam um campo de conhecimento. $\mathrm{O}$ discurso interdisciplinar tem como fundamento uma aparente homogeneidade lógica, utilizando de estratégias ideológicas em formações discursivas pautadas no generalismo e no naturalismo. Esse discurso tão propalado representa uma porta aberta ao pensamento ingênuo e a práticas supostamente integradoras, que, longe de constituir efetivas contribuições teórico-metodológicas orientadas à construção da autonomia do campo, podem estar apenas a serviço do controle de fluxos de informação e conhecimento. A transdisciplinaridade, que parece ser o horizonte do modelo de desenvolvimento da ciência contemporânea, constitui um simulacro do exercício interdisciplinar errante comprometido com a nova topologia dos mercados.

O forte vínculo da ciência da informação com as novas tecnologias não a deixa alheia à desterritorialização do poder, aos fluxos de capitais e às necessidades de informação e conhecimento para manter esses processos. De forma mais precisa, pode-se dizer que o seu forte vínculo com a revolução informacional, com o novo modelo de desenvolvimento econômico e com a ciência contemporânea, desconsiderando as particularidades de seu campo de conhecimento e de seu objeto de estudo específico, bem como das teorias e metodologias, em um movimento de busca incessante de relações interdisciplinares, representa a aceitação acrítica das proposições gerais e aparentemente estabilizadas. Essa postura colabora tanto com a flutuação conceitual, teórica, metodológica e prática presente no campo da ciência da informação, quanto com a dificuldade de construção de sua identidade.

O discurso da integração disciplinar, na ciência da informação, é permeado por mais de uma formação discursiva, mas encontra-se ancorado em um metadiscurso, que tem por base as determinações do modo de desenvolvimento informacional. Assim, pode-se observar que os sujeitos discursivos falam a partir de um lugar marcado pelas determinações da ciência contemporânea como produto da sociedade capitalista e seu respectivo modo de desenvolvimento, o informacionalismo. Malgrado a formação ideológica que sustenta esse discurso pareça apagar a heterogeneidade e camuflar os conflitos presentes por intermédio de estratégias discursivas lógico-práticas de ordem naturais, substanciais e gerais, é possível observar as lacunas e marcas da distância discursiva, conforme sugere Pêcheux (1990). A interdisciplinaridade, na ciência da informação, é apresentada em um espaço logicamente estabilizado, desconsiderando as tensões, disputas e negociações que existem no campo de lutas e forças que as constituem, com toda a carga de determinações sociais, políticas, econômicas e histórico-ideológicas. 
Com efeito, do ponto de vista epistemológico, evidencia certa fragilidade nos processos de integração disciplinar, sobretudo interno, uma vez que, longe de se constituir em fundamentos de práticas integradoras, o discurso interdisciplinar, na ciência da informação, tem por base um metadiscurso contemporâneo homogeneizador que camufla o seu compromisso com a tecnociência e o controle dos fluxos de informação e conhecimento, em detrimento de efetivas contribuições teórico-metodológicas orientadas à construção de sua autonomia. Nessa perspectiva, a interdisciplinaridade que vem sendo construída na ciência da informação se constitui em entrave ao processo de consolidação epistemológica, na medida em que esta se disciplina em torno de um jogo subversivo da tecnociência em detrimento das necessidades de seu campo epistemológico.

\section{Agradecimentos}

Agradecemos à Fundação de Amparo à Pesquisa do Estado de Alagoas (FAPEAL) pelo financiamento concedido, que vem se constituindo em importante suporte para a realização desta pesquisa.

Artigo submetido em 21/11/2010 e aceito em 12/03/2012.

\section{REFERÊNCIAS}

ARAÚJO, C. A. A. Correntes teóricas da ciência da informação. ciência da informação, Brasília, v. 38, n. 3, p. 194-204, set. dez., 2009. Disponível em: <http://revista.ibict.br/index.php/ciinf/article/view/1719 >. Acesso em: 15 jul. 2010.

BACHELARD, G. A formação do espirito científico: contribuições para uma psicanálise do conhecimento. Rio de Janeiro: Contraponto, 1996. 314p.

BORKO, H. Information science: what is it? American Documentation, Chicago, v.19, n.1, p.3-5, jan. 1968.

BOURDIEU, P. O campo científico. In: ORTIZ, R. (Org.). Pierre Bourdieu: Sociologia. São Paulo: Ática, 1983. Cap. 2, p. 122-155.
BRANDÃO, C. A. L. A traduzibilidade dos conceitos: entre o visível e o dizível. In: DOMINGUES, I. (Org.). Conbecimento e transdisciplinaridade II: aspectos metodológicos. Belo Horizonte: Editora da UFMG, 2005. Cap. 2, p. 41-100.

CAPURRO, R. Epistemologia e ciência da informação. In: ENCONTRO NACIONAL DE PESQUISA EM ciência da informação, 5, 2003, Belo Horizonte. Anais... Belo Horizonte, UFMG, 2003. 1 CD-ROM.

CASTELLS, M. A sociedade em rede. 4. ed. São Paulo: Paz e Terra, 2000. 617p.

DIAS, E. W. Biblioteconomia e ciência da informação. Perspectivas em ciência da informação, Belo Horizonte, v. 5, n. especial, p. 60-80, jan./ jun. 2000.

DOMINGUES, I. Em busca do método. In: DOMINGUES, I. (Org.). Conhecimento e transdisciplinaridade II: aspectos metodológicos. Belo Horizonte: Editora da UFMG, 2005. Cap. 1, p. 17-40.

DOMINGUES, I. et al. Um novo olhar sobre o conhecimento. In: DOMINGUES, I. (Org.). Conbecimento e transdisciplinaridade. Belo Horizonte: Editora da UFMG/IEAT, 2004. p. 13-27.

FLORỀnCIO, A. M. G. et al. Análise do discurso: fundamentos \& prática. Maceió: Edufal, 2009. 131p.

GONZÁLEZ DE GÓMEZ, M. N. Metodologia da pesquisa no campo da ciência da informação. Data grama zero - revista de ciência da informação, v. 1, n. 6, dez. 2000. Disponível em: < http://dgz.org.br/ dez00/F I art.htm>. Acesso em: 25 ago. 2009.

KUHN, T. A estrutura das revoluções cientificas. São Paulo: São Paulo: Perspectiva, 2007. 260p.

LE COADIC, Y. F. A ciência da informação. Brasília: Briquet de Lemos Livros, 1996. 119p.

LYOTARD, J. A condição pós-moderna. 6. ed. Rio de Janeiro: José Olympio, 2000. 131p. 2007. 120p.

Introdução ao pensamento complexo. 3. ed. Porto Alegre: Sulina,

ORLANDI, E. P. Análise de Discurso: princípios e procedimentos. 3. ed. Campinas, SP: Pontes, 2001. 100p.

PÊCHEUX, M. O discurso: estrutura ou acontecimento. Capinas, SP: Pontes, 1990. 65p.

PINHEIRO, L. V. R. Processo evolutivo e tendências contemporâneas da ciência da informação. Informação e sociedade: estudos, João Pessoa, v. 15, n. 1, p. 13-48, jan./jun. 2005. Disponível em: <http://www. ies.ufpb.br/ojs2/index.php/ies/article/view/51/1521>. Acesso em: 25 ago. 2009.

POMBO, O. Epistemologia interdisciplinar. In: SEMINÁRIO INTERNACIONAL INTERDISCIPLINARIDADE, HUMANISMO, UNIVERSIDADE. Porto, 2003. Anais... Porto, 2003. p. 1-29. Disponível em: $<$ http://www.humanismolatino.online. pt/v1/pdf/C002_11.pdf $>$. Acesso em: 16 set. 2008. 
RENDON ROJAS, M. A. La ciencia de la información en el contexto de las ciencias sociales y humanas. Ontología, epistemología, metodología e interdisciplina. Data grama zero - revista de ciência da informação, v. 9, n. 4, dez. 2008. Disponível em: < $\underline{\text { http://dgz.org.br/ }}$ ago08/Art_06.htm>. Acesso em: 25 ago. 2009.

SANTOS, B. S. Um discurso sobre as ciências. São Paulo: Cortez, 2003. 92p.

SARACEVIC, T. ciência da informação: origens, evolução e relações. Perspectivas em ciência da informação. Belo Horizonte, v. 1, n. 1, p. 41-62, jan./jun. 1996.

Information Science. In: BATES, M. J.; MAACK, M. N. (Eds). Encyclopedia of Libray of Information Science. New York: Taylor e Francis, 2009.

Information Science. Journal of the American Society for Information SciEnce, v. 50, n. 12, p. 1051-1063, 1999.

Information Science: origen, evolution and relations. In: VAKKARI, P.; CRONIN, B. Conceptions of Library and Informations Science: historical, empirical and theoretical perspectives. London: Taylor Graham, 1992. p. 5-27.

Interdisciplinary nature of Information Science. Ciência da informação, Brasília, v. 24, n. 1, p. 36-41, 1995.

SILVA, E. M. P. Os caminhos da transdisciplinaridade. In: DOMINGUES, I. (Org.). Conhecimento e transdisciplinaridade. Belo Horizonte: Editora da UFMG/IEAT, 2004. p. 35-43.

TÁLAMO, M. F. G.; SMIT, J. T. ciência da informação: pensamento informacional e integração disciplinar. Brazilian journal of Information Science, v. 1, n. 1, p. 33-57, 2007. Disponível em: <http://www2. marilia.unesp.br/revistas/index.php/bjis/article/viewFile/30/29>. Acesso em: 20 ago. 2010.

WERSIG, G. Information Science and theory: a weaver bird's perspective. In: VAKKARI, P.; CRONIN, B. Conceptions of Library and Information Science: historical, empirical and theoretical perspectives. London: Taylor Graham, 1992. p. 201-217.

WHITE, H.D.; MCCAIN, K.W. Visualizing a discipline: An author cocitation analysis of information science. 1972 - 1995. Journal of the American Society of Information Science, v. 49, n. 4, p. 327-355, 1998.

\section{APÊNDICE A: CORPUS ANALÍTICO}

FREIRE, I. M. Da construção do conhecimento científico à responsabilidade social da ciência da informação. Informação e sociedade: estudos, João Pessoa, v. 12, n. 1, 2002. Disponível em: < $\underline{\text { http://www. }}$ ies.ufpb.br/ojs2/index.php/ies/article/view/158/152>. Acesso em: 25 ago. 2009.

. O olhar da consciência possível sobre o campo científico. Ciência da informação, Brasília, v. 32, n. 1, p. 50-59, jan./abr. 2003. Disponível em: < $\underline{\text { http://revista.ibict.br/ciinf/index.php/ciinf/ }}$ article/view/130/111>. Acesso em: 25 ago. 2009.
; ARAÚJO, V.M. H. Tecendo a rede de Wersig com os indícios de Ginzburg. Data grama zero - revista de Ciência da Informação, v. 2, n. 4, ago. 2001. Disponível em: < http://www.datagramazero.org.br/ ago01/Art 03.htm>. Acesso em: 25 ago. 2009.

GONZÁLEZ DE GÓMEZ, M. N. Escopo e abrangência da ciência da informação e a pós-graduação na área: anotações para uma reflexão. Transinformação, Campinas, v. 15, n. 1, p. 31-43, jan./ abr. 2003. Disponível em: <http://biblioteca.ricesu.com.br/ler. php?art cod=1362>. Acesso em: 25 ago. 2009.

Metodologia da pesquisa no campo da ciência da informação. Data grama žero - revista de Ciência da Informação, v. 1, n. 6, dez. 2000. Disponível em: < http://dgz.org.br/dez00/F I art.htm>. Acesso em: 25 ago. 2009.

- Para uma reflexão epistemológica acerca da ciência da informação. Perspectivas em ciência da informação, Belo Horizonte, v. 6, n. 1, p. 5-18, jan./jun. 2001. Disponível em: < http://www.eci.ufmg. br/pcionline/index.php/pci/article/view/433/243>. Acesso em: 25 ago. 2009.

KOBASHI, N. Y.; SMIT, Y. W.; TÁLAMO, M. F. G. M. A função da terminologia na construção do objeto da ciência da informação. Data grama zero - revista de Ciência da Informação, v. 2, n. 2, abr. 2001. Disponível em: < http://www.dgz.org.br/abr01/Art 03.htm $>$. Acesso em: 25 ago. 2009.

KOBASHI, N. Y.; TÁLAMO, M. F. G. M. Informação: fenômeno e objeto de estudo da sociedade contemporânea. Transinformação, Campinas, v. 15, n. especial, p. 7-21, set./dez. 2003. Disponível em: $<$ http://biblioteca.ricesu.com.br/ler.php?art cod=476 $>$. Acesso em: 25 ago. 2009.

PINHEIRO, L. V. R. Processo evolutivo e tendências contemporâneas da ciência da informação. Informação e sociedade: estudos, João Pessoa, v. 15, n. 1, p. 13-48, jan./jun. 2005. Disponível em: < http://www. ies.ufpb.br/ojs2/index.php/ies/article/view/51/1521>. Acesso em: 25 ago. 2009.

; LOUREIRO, J. M. M. Traçados e limites da ciência da informação. Ciência da informação, Brasília, v. 24, n. 1, 1995. Disponível em: < http://revista.ibict.br/index.php/ciinf/article/ view/531/483 >. Acesso em: 25 ago. 2009.

SMIT, Y. W.; TÁlAMO, M. F. G. M.; KOBASHI, N. Y. A determinação do campo da ciência da informação: uma abordagem terminológica. Data grama zero - revista de Ciência da Informação, v. 5, n. 1, fev. 2004. Disponível em: < http://www.datagramazero.org.br/ fev04/Art_03.htm>. Acesso em: 25 ago. 2009.

TARGINO, M. G. A interdisciplinaridade da ciência da informação como área de pesquisa. Informação e sociedade: estudos, João Pessoa, v. 5, n. 1, p. 12-17, jan./dez. 1995. Disponível em: < http://www.ies. ufpb.br/ojs2/index.php/ies/article/view/196/1419>. Acesso em: 25 ago. 2009. 